\title{
A Literature Review on Knowledge Sharing
}

\author{
Tingting Zheng \\ School of Management, Jinan University, Guangzhou, China \\ Email:ztt_35@163.com
}

How to cite this paper: Zheng, T.T. (2017) A Literature Review on Knowledge Sharing. Open Journal of Social Sciences, $\mathbf{5}$, 51-58.

https://doi.org/10.4236/jss.2017.53006

Received: February 11, 2017

Accepted: March 13, 2017

Published: March 16, 2017

Copyright $\odot 2017$ by author and Scientific Research Publishing Inc. This work is licensed under the Creative Commons Attribution International License (CC BY 4.0).

http://creativecommons.org/licenses/by/4.0/

\begin{abstract}
Knowledge is the organization's most important strategic resource that can provide organizations with a sustainable competitive advantage; at the same time, knowledge management depends on knowledge sharing. Knowledge sharing is affected by multi-level factors: Organizational level, team level and individual level factors; some will promote knowledge sharing, and some will have a negative impact. Therefore, this paper reviews the concepts of knowledge sharing and the related factors that affect knowledge sharing. Finally, this paper proposes future research directions about knowledge sharing.
\end{abstract}

\section{Keywords}

Knowledge Sharing, Formation Process, Influential Factors

\section{Introduction}

Ipe \& Minu (2003) showed that knowledge was the organization's most important strategic resource; it could provide enterprises with sustainable competitive advantage in a competitive dynamic economy. As the knowledge is the most important factor in today's organizations, the facilitation of the creation, sharing, and the utilization of knowledge becomes more and more important [1]; so we need to pay attention to the knowledge management; this knowledge management is considered to have a major influence on organization's success [1]. In order to maintain competitive advantage, organizations rely on staff and training systems. This system is focused on the selection of specific knowledge, skills, abilities or helping employees get this particularity, namely, knowledge management. Knowledge management system tries to lead and support the flow of ideas and experience of the members [2]. Renzl, Birgit (2008) showed that knowledge sharing within a team or between teams was crucial for organizations to develop the skills and capabilities, to enhance the value and sustain competitive advantage [3]; knowledge sharing behavior was the basis means that employees can contribute to the application of knowledge, innovation and optimization of the 
organizational [4]. So knowledge sharing plays an increasingly important role in knowledge management outcomes [5]. It is an important gathering in the field of knowledge management [6]. As knowledge sharing has such a great potential benefits, many organizations have invested a lot of time and money to the knowledge management.

\section{Knowledge Sharing Related Concepts}

\subsection{Definition}

Knowledge sharing is different from knowledge transfer and knowledge exchange. While "knowledge exchange" has been used interchangeably with "knowledge sharing", knowledge transfer involves the sharing of knowledge source and the acquisition of knowledge source. Knowledge transfer is used to describe the moving between different units, departments, organizations [4].

Knowledge sharing is not communication, but related to the communication, so does information distribution [6]. In the strict sense, knowledge cannot be shared, so you can't freely distribute knowledge, unlike goods, it relies on a cognitive subject. In order to gain knowledge from others, rebuilding behavior indispensable. It uses knowledge to acquire knowledge, thus sharing knowledge. Sharing knowledge is assumed to be at least a relationship between the two parties, one side is to have knowledge, and the other side to acquire knowledge [6].

Connelly (2000) defined knowledge sharing as the exchange of knowledge, or the behavior that help others with knowledge. Ipe (2003) thought that the knowledge sharing between individuals was the process that private individuals knowledge turn to be understood, absorbed and used by others [1]. It means that knowledge sharing is at least a conscious behavior, and knowledge sources also don't want to give up ownership of knowledge.

From the above definition of knowledge sharing, knowledge sharing, we can sum up the basic characteristics are: 1) knowledge sharing is a major individual behavior; 2) knowledge sharing is a voluntary, proactive, behavioral awareness; 3) knowledge sharing is controlled by environmental systems or procedures, such as legal, ethical standards and code of conduct, habits; 4) the result of knowledge sharing knowledge is to be jointly occupied by two or more parties [7].

\subsection{The Formation Process}

Davenport and Prusak's (1998) proposed a knowledge-sharing formula: Share = pass + absorb. Subsequently, Hendriks, Paul (1999) proposed the formation of knowledge sharing process had two sub-processes: First, knowledge sharing assumes that owner has a externalizing behavior [6]. The process of the externalization takes many forms. Knowledge externalization is not a conscious action, they did not design to share knowledge with others; second, as shown in Figure 1 [6], knowledge sharing assumed knowledge winner (the figure for the knowledge restorer) has a internalized behavior.

Internalization appears in different forms, such as learning by doing, reading or trying to understand the explicit knowledge in the knowledge base. But there 
are obstacles to hinder the internalization of the external knowledge, such as the barriers of time and space, as well as from the different social, cultural, linguistic and spiritual and conceptual framework [6].

\section{Factors Affecting Knowledge Sharing}

\subsection{Organizational Level}

De Long \& Fahey (2000) discovered the benefits of the new technology infrastructure would be limited when long-standing organization values and practice didn't support knowledge sharing based on a qualitative study of 50 companies. This shows that the organizational factors of knowledge sharing play a significant role [8].

\subsubsection{Technical}

A KMS developer in Ernst \& Young said: "If people do not want to share, even if giving them the world's best technology is useless". Thus it can be seen, although information technology is not the important document in knowledge management, it can make knowledge sharing more efficient. Because companies can't have long-term human capital, so there are many companies choose to use information technology to facilitate knowledge sharing to retain organizational knowledge and to facilitate knowledge rosing from the individual level to the organizational level [9].

Cabrera, Ángel Cabrera \& Elizabeth F (2002) pointed out that knowledge management projects largely led by IT departments [10], so the technology was an important part of knowledge management. Researchers have emphasized the importance of information technology infrastructure and applications in organization contact information.

The technology also includes many aspects, Alavi \& Leidner (2001) showed that IT increased knowledge transfer by extending individual beyond the formal communication channels, such as: computer networks, electronic bulletin boards, etc. [11].

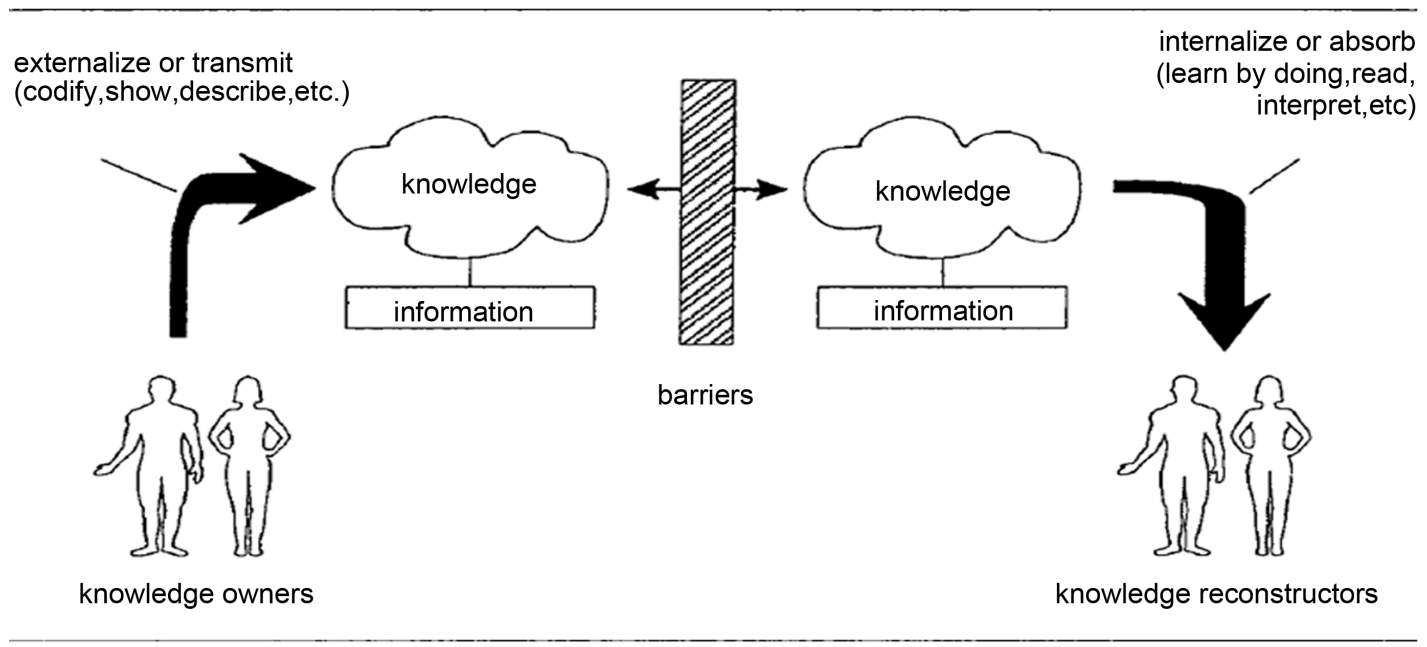

Figure 1. A simple model of knowledge sharing. Source: [6], p. 93. 


\subsubsection{Creative}

Recently, Chinese researcher did a study of organizational creative culture having a multi-level effect on individual knowledge sharing [12]. The study showed that organizations with creative culture would support staff interaction to encourage them share experiences, know-how, ideas and other tacit knowledge. So, in the end of the study the researcher recommend company to pay more attention to the culture of creative and the exchange of ideas that can positively affect the action of knowledge management. In other words, innovation culture is the most important factor to promote knowledge sharing [12].

\subsubsection{Competition}

The culture that encourage individuals to compete successfully dominates will have a negative effect on knowledge sharing [4]. It means that the organizational climate which emphasis on individual competition will become knowledgesharing's obstacles, on the contrary, sense of organization cooperation will help to build trust, which is a necessary condition for knowledge sharing [4].

\subsubsection{Fair}

Fair is important to the sharing of knowledge. Procedural fairness would be an employee of cognitive knowledge sharing's positive impact. Lin (2007) found that distributive justice and procedural fairness would have a direct positive effect on sharing tacit knowledge by organizational commitment, also distributive justice would influence knowledge sharing through the trust among colleagues [4]. To sum up, fair is a very important factor that influence the knowledge sharing.

\subsection{Team Level}

\subsubsection{Shared Mental}

Shared mental model means team members have similar or compatible knowledge structure for the related things within the team. It is clear that this knowledge structure helps members to describe, interpret and predict events in the context and guide members to interact with other members in the desired context [13]. Most of the past empirical research found that shared mental model among the members helped each other in the coordination and integration, contributed to the mutual cooperation and coordination among the members, therefore, shared mental model has a positive effect on team effectiveness [13], finally it can have a positive effect on knowledge sharing.

\subsubsection{Team Memebers' Diversity}

From the perspective of independent variables, researchers have different classification methods for team diversity, such as demographic variables or individual characteristics. The former refers to the long lasting features, such as gender, race, age, etc. the latter is the characteristics of subjective understanding, such as cognition, attention and so on. Besides, many researchers use the former characteristics to replace the latter characteristics, because the latter characteristics are hard to be measured [14]. 
Knowledge sharing requires a good interaction between team members, more communication opportunities and willingness. When the difference of team members are too large, may hinder knowledge sharing among members [15]. Ojha (2005) showed that if the team members thought that they were the few people in their team, such as: gender, marital status, level of education of the minority, then they were less prone to knowledge sharing. Studies had shown that isolated members of society were less likely to agree with the others, and they would not contribute their knowledge in a heterogeneous team [16].

\subsection{Individual Level}

\subsubsection{Personality}

Personal characteristics such as age, education and work experience that is likely to slow the relationship between knowledge promoter and process [17]. Personality will have an impact on knowledge sharing.

1) Openness Personality

Research shows that if individual has high openness, he tends to have a high level of curiosity to seek other people's ideas and opinions. On the contrary, the members with high introversion trait make them lonely, live alone, not good at communication and have a tendency to avoid social [18], this is not good for knowledge sharing.

2) Proactive Personality

Proactive personality refers to a stable tendency that the individual is not bound by the existing environment, they can explore new ways to affect the external environment through the active behavior [19]. According to a survey of 199 employees, researcher shows that the proactive personality has the positive effect on the knowledge sharing [19].

3) Responsibility Personality

Cabrera \& Cabrera (2002) thought that the individual responsibility contributed to the smooth implementation of knowledge management systems [10], personal responsibility was regarded as an important personality characteristic factors included in the study of knowledge sharing system.

\subsubsection{Intrinsic Motivation}

Yoon, Cheolho, Rolland \& Erik (2012) based on self-determination theory, investigated the effect of three basic psychological needs for knowledge sharing factors, the results showed the ability and sense of belonging had a positive impact on knowledge sharing behavior, and although the sense of autonomy had a positive effect, not significant [20]. Meeting the psychological needs can promote intrinsic motivation, and this will enhance the results also reflect the intrinsic motivation to share knowledge to generate a positive impact.

In addition, one of the motive factor is fear, Szulanski noted that knowledge holders generally had a monopoly and exclusive mentality, which was the main reason for their lack of willingness to share. Knowledge holders fear superiority and some special interests lost by knowledge sharing, worried inequities exist in 
the "knowledge exchange", and which leads to the sharing of knowledge being difficult [9].

\subsubsection{The Social Capital}

Knowledge sharing will be embedded in the vast network of organizations, such as: communities of practice [4]. Chiu et al. (2006) study showed that in a virtual community, individuals having the direct contacts and relationships with other members had a positive impact on sharing knowledge [21]. In social networks, relationships are in an important part. The trust also affects knowledge sharing. Bakker et al. (2006) divided credibility into three dimensions: competence, integrity and kindness. Research showed that when people thought team members were very capable, individuals would be less tendency to share knowledge, while they believed that the team members were honest, fair, honest, and they were more inclined to share knowledge [4].

To sum up, this paper constructs a model as Figure 2.

\section{Conclusions}

Knowledge is the most important strategic resource of the 21st century. This paper reviewed the concept of knowledge sharing, formation and influencing factors. We can see the importance of knowledge sharing and it is influenced by many factors, which provides a theoretical basis for enterprises to enhance knowledge sharing.

However, knowledge sharing study also has some limitations; researchers need to continue to study the relevant areas of knowledge sharing.

First, knowledge sharing's measurement standard is still uncertainty.

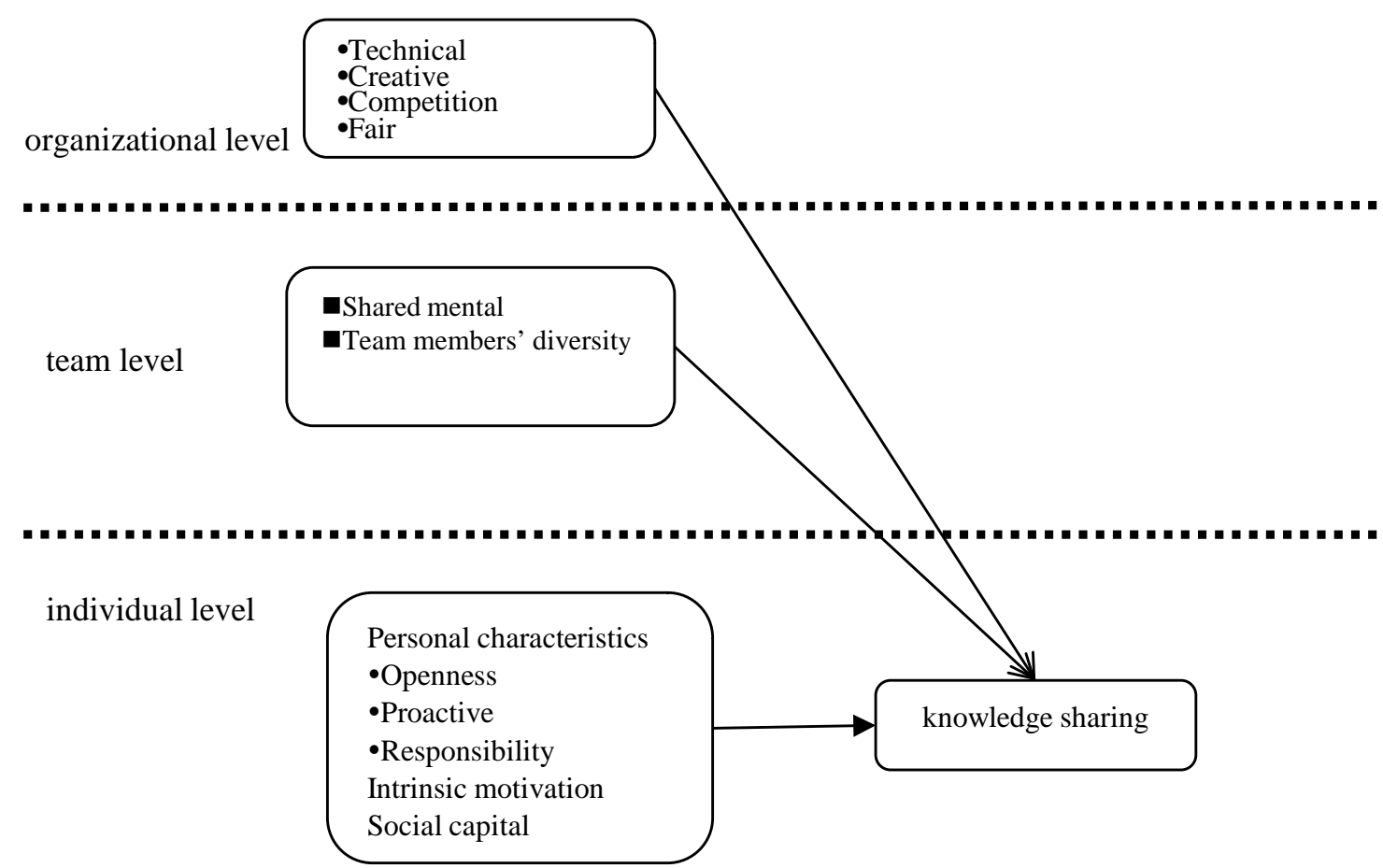

Figure 2. Influential factors of knowledge sharing's formation. 
Second, it can be seen from the above; among the influencing factors of knowledge sharing, the study about personal characteristics factors is relatively less. In fact, this should be a focus of the study; demographic characteristics are a very important research direction. Each individual has own unique understanding of action, because each person's perception of external things can be seen as a gradual process: personal vision is limited; they only have selective observation, and interpretation of relevant information after filtration using the existing cognitive structure and values formation [14]. Therefore, the demographic characteristics is a direction worthy of study; to study the demographic characteristics, you can use the relevant demographic indicators such as age, organizational tenure, professional background, education, gender, ethnicity, and socio-economic background.

Finally, the study should be done for different organization types. Different organization types have different characteristics; knowledge sharing will produce different effects on organizational.

\section{References}

[1] Ipe, M. (2003) Knowledge Sharing in Organizations: A Conceptual Framework. Human Resource Development Review, 2, 337-359. https://doi.org/10.1177/1534484303257985

[2] Cabrera, Á., Collins, W.C. and Salgado, J.F. (2006) Determinants of Individual Engagement in Knowledge Sharing. International Journal of Human Resource Management, 17, 245-264. https://doi.org/10.1080/09585190500404614

[3] Renzl, B. (2008) Trust in Management and Knowledge Sharing: The Mediating Effects of Fear and Knowledge Documentation. Omega, 36, 206-220. https://doi.org/10.1016/j.omega.2006.06.005

[4] Wang, S. and Noe, R.A. (2010) Knowledge Sharing: A Review and Directions for Future Research. Human Resource Management Review, 20, 115-131. https://doi.org/10.1016/j.hrmr.2009.10.001

[5] Yang, C. and Chen, L. (2007) Can Organizational Knowledge Capabilities Affect Knowledge Sharing Behavior? Journal of Information Science, 33, 95-109. https://doi.org/10.1177/0165551506068135

[6] Hendriks, P. (1999) Why Share Knowledge? The Influence of ICT on the Motivation for Knowledge Sharing. Knowledge \& Process Management, 6, 91-100. https://doi.org/10.1002/(SICI)1099-1441(199906)6:2<91::AID-KPM54>3.0.CO;2-M

[7] Peng, W. (2010) Research on the Influence of Contextual Performance Based on the Employee's Social Network Feature and Knowledge Sharing. Sun Yat-sen University, Guangzhou.

[8] De Long, D.W. and Fahey, L. (2000) Diagnosing Cultural Barriers to Knowledge Management. Academy of Management Executive, 14, 113-127. https://doi.org/10.5465/ame.2000.3979820

[9] Yi, W., Qing, X., Lijun, M., et al. (2008) Influential Factors to Knowledge Sharing between Intra-Organizational Members. A Literature Review. Journal of Xidian University, 4, 46-52.

[10] Cabrera, Á. and Cabrera, E.F. (2002) Knowledge-Sharing Dilemmas. Organization Studies, 23, 687-710. https://doi.org/10.1177/0170840602235001

[11] Kim, S. and Lee, H. (2006) The Impact of Organizational Context and Information 
Technology on Employee Knowledge-Sharing Capabilities. Public Administration Review, 66, 370-385. https://doi.org/10.1111/j.1540-6210.2006.00595.x

[12] Li, Y., Liu, Z. and Lin, Y. (2016) Where Is the Driving Force of Employee's Knowledge Sharing? The Multilevel Effect of Innovative Culture. Economic Management, No. 5, 75-86.

[13] Qian, C. (2010) The Structural Analysis of Knowledge Sharing in Team and Influencing Factors. Nankai Business Review, 13, 36-44.

[14] Hambrick, D.C. (2007) Upper Echelons Theory: An Update. Academy of Management Review, 32, 334-343. https://doi.org/10.5465/AMR.2007.24345254

[15] Liu, N. and Jia, J. (2012) An Empirical Study on Team Diversity, Knowledge Sharing and Innovation Performance in R\&D Teams. Nankai Business Review, No. 6, 85-92.

[16] Ojha, A.K. (2005) Impact of Team Demography on Knowledge Sharing in Software Project Teams. South Asian Journal of Management, 12, 67-78.

[17] Lin, H.-F. (2007) Knowledge Sharing and Firm Innovation Capability: An Empirical Study. International Journal of Manpower, 28, 315-332. https://doi.org/10.1108/01437720710755272

[18] Zhou, Z., Zhang, J. and Xiong, Y. (2014) How Do Introversion-Extraversion Personality Traits Influence Knowledge Sharing Behavior in Online Brand Communities: The Mediation of Network Centrality and Reciprocity Norm. Nankai Business Review, 17, 19-29.

[19] Zhang, Z., Yu, C. and Li, Y. (2016) The Relationship among Proactive Personality, Knowledge Sharing and Employee's Innovation Behavior. Management Review, 28, 123-133.

[20] Yoon, C. and Rolland, E. (2012) Knowledge-Sharing in Virtual Communities: Familiarity, Anonymity and Self-Determination Theory. Behaviour \& Information Technology, 31, 1133-1143. https://doi.org/10.1080/0144929X.2012.702355

[21] Chiu, C., Hsu, M. and Wang, E.T.G. (2006) Understanding Knowledge Sharing in Virtual Communities: An Integration of Social Capital and Social Cognitive Theories. Decision Support Systems, 42, 1872-1888.

https://doi.org/10.1016/j.dss.2006.04.001

\section{Submit or recommend next manuscript to SCIRP and we will provide best service for you:}

Accepting pre-submission inquiries through Email, Facebook, LinkedIn, Twitter, etc. A wide selection of journals (inclusive of 9 subjects, more than 200 journals)

Providing 24-hour high-quality service

User-friendly online submission system

Fair and swift peer-review system

Efficient typesetting and proofreading procedure

Display of the result of downloads and visits, as well as the number of cited articles

Maximum dissemination of your research work

Submit your manuscript at: http://papersubmission.scirp.org/

Or contact jss@scirp.org 